\title{
El Proyecto Mesoamérica: ¿Éxito o fracaso? \\ LÍMITES DE LA COOPERACIÓN DE MÉXICO \\ hacia Centroamérica ${ }^{1}$
}

\section{The Mesoamerica Project: Success or Failure? \\ LIMITS OF COOPERATION FROM MEXICO \\ to Central America}

\section{Mónica Toussaint ${ }^{2}$ Marisol Garzón ${ }^{3}$}

Resumen: En las últimas décadas, la relación de México con Centroamérica dejó de lado los asuntos de índole política para centrar su interés en la firma de convenios y tratados de libre comercio, así como en el impulso de programas de cooperación para el desarrollo regional, como el Plan Puebla Panamá y el Proyecto Mesoamérica. Sin embargo, partimos de la hipótesis de que los resultados de los proyectos de cooperación no han sido del todo exitosos y parecen haber dejado de lado dos de los principales aspectos de la dinámica fronteriza en el sur de México, así como en los países de la región centroamericana: la migración y la violencia. Por ello, a partir de un recorrido por la historia de ambos fenómenos en las últimas décadas, este artículo tiene como objetivo analizar el papel de los acuerdos bilaterales y los proyectos de cooperación hacia Centroamérica impulsados por México, con el fin de evaluar en

\footnotetext{
${ }^{1}$ Nota del editor: se respeta íntegramente el texto final que entregaron las autoras, con los dictámenes académicos atendidos.

${ }^{2}$ Doctora en Estudios Latinoamericanos por la Facultad de Filosofía y Letras de la UNAM y profesora-investigadora del Área de Estudios Internacionales del Instituto de Investigaciones Dr. José María Luis Mora. Correo electrónico: mtoussaint@institutomora.edu.mx

${ }^{3}$ Maestra en Historia Moderna y Contemporánea por el Instituto de Investigaciones Dr. José María Luis Mora y asistente de investigación de la Dirección de Docencia. Correo electrónico: marisol_garzonrivera@hotmail.com

Fecha de recepción: 2701 17; Fecha de aceptación: 070517.
}

(cc) BY-NC-ND Páginas 15-52. 
qué medida han logrado incidir en la solución de los problemas económicos y sociales de la región, o si su desarrollo ha estado determinado por otros intereses.

Palabras clave: política exterior, acuerdos bilaterales, proyectos de cooperación, migración, violencia.

Abstract: During the last decades, the relationship between Mexico and Central America left aside political affairs in order to focus its interest both in signing conventions and free trade agreements as in the promotion of cooperation programs for regional development, such as the Puebla Panama Plan and the Mesoamerica Project. However, our hypothesis is that the results of the cooperation programs have not been entirely successful and that they seem to have set aside two of the main aspects of the border dynamics in the South of Mexico, as well as in the countries of the Central American region: migration and violence. Therefore, from a journey through the history of both phenomena in recent decades, this article aims to analyze the role of bilateral agreements and cooperation to Central America projects driven by Mexico, in order to assess to what extent have managed to have an impact on the solution of the economic and social problems of the region, or if their development has been determined by other interests.

Keywords: foreign policy, bilateral agreements, cooperation projects, migration, violence.

\section{Introducción}

A finales de los años setenta y principios de los ochenta del siglo XX, México desarrolló una política exterior activa hacia Centroamérica con el objetivo de dar apoyo a los movimientos sociales que buscaban un cambio político en la región. Posteriormente, los gobiernos mexicanos enfocaron sus esfuerzos diplomáticos en las negociaciones para alcanzar la paz en el istmo centroamericano, por medio del Grupo Contadora, creado por iniciativa de México en 1983. Después del fracaso en la firma 
del Acta de Paz de Contadora en 1986, el gobierno mexicano optó por trasladar la responsabilidad y la gestión de este proceso a los propios países centroamericanos. Las negociaciones de paz en Centroamérica culminaron con la firma de los Acuerdos de Chapultepec, entre el Frente Farabundo Martí para la Liberación Nacional (FMLN) y el gobierno de El Salvador, en 1992, y el Acuerdo de Paz entre el gobierno de Guatemala y la Unidad Revolucionaria Nacional Guatemalteca (URNG), en 1996.

A partir de entonces, México resolvió dejar de lado la diplomacia activa en Centroamérica para emprender la construcción de mecanismos de cooperación para el desarrollo regional, tales como las Cumbres de Tuxtla, el Plan Puebla Panamá y el Proyecto Mesoamérica. Asimismo, promovió la negociación de tratados de libre comercio con los países del istmo, como una manera de apuntalar esta relación. Sin embargo, los resultados de los programas de cooperación no han sido del todo claros. Al preguntarnos acerca de la forma en que México ha enfrentado dos de los principales aspectos que impactan la dinámica políticosocial de su frontera sur, la migración y la violencia, encontramos que los proyectos de cooperación promovidos hasta ahora han estado más dirigidos a la creación de infraestructura para favorecer el libre tránsito de mercancías y abrir las puertas a los capitales privados, que a contribuir a resolver las causas estructurales de los problemas sociales que dan sustento al fenómeno migratorio y a buscar una salida conjunta a la creciente situación de violencia en la región.

A lo largo de su historia, Centroamérica ha sido escenario de importantes problemas sociales, estructurales y coyunturales. Por una parte, constituye una región en la que existen elevados niveles de pobreza, ${ }^{4}$ así como profundas condiciones de marginación y exclusión social. Es, de hecho, la región con mayor desigualdad en el mundo. ${ }^{5}$ En

\footnotetext{
${ }^{4}$ Los países de la región se han caracterizado por tener un elevado porcentaje de su población en situación de pobreza: en 2002, el porcentaje de la población de El Salvador en situación de pobreza fue del 48.8\%; en Guatemala era del $54.3 \%$; en Honduras del 77.0\%; y en Nicaragua del 69.3\%; por su parte, en el mismo periodo el porcentaje de la población en situación de pobreza en México era del 39.3\% (Comisión Económica para América Latina y el Caribe, 2015: 18).

${ }^{5}$ Los países de Centroamérica tienen una distribución del ingreso más desigual que otros; de acuerdo con el Coeficiente Gini, cuyo valor de 1.00 representa desigualdad absoluta, entre 2003
} 
el pasado reciente, estos factores estructurales dieron origen a escenarios de violencia política y guerras civiles en los países de la región y, ya en el contexto de la posguerra, no sólo persistieron, sino que muchas veces se agudizaron, tanto por los efectos devastadores de la guerra, como por la implementación del proyecto neoliberal desde finales de los años ochenta y principios de los noventa del siglo pasado.

La persistencia y agudización de dichos factores estructurales y el deterioro de las condiciones de vida de la población dieron lugar a otros problemas sociales, entre ellos, el fenómeno de la migración. En la actualidad, cientos de centroamericanos salen cada día de sus países buscando mejores opciones de vida y huyendo de la realidad de pobreza y marginación en sus lugares de origen, tal como también ocurrió en el pasado a causa de la violencia de la guerra. Pero, además de lo ya señalado, en los años recientes la región ha estado inmersa en una situación de violencia extrema. El cese de las guerras civiles en Centroamérica en los años noventa, coincidió con un estallido de violencia social en el contexto de posguerra, que se debió en gran medida a las limitaciones de los procesos de pacificación y desmovilización que, entre otras cosas, no lograron insertar eficazmente a la vida civil a los viejos actores armados, dejaron una gran proliferación de armas de fuego remanentes de la guerra y no resolvieron los problemas estructurales que en el pasado habían dado origen a los conflictos.

Al iniciar el siglo XXI, Centroamérica experimentó una nueva oleada de violencia caracterizada por elevados índices de homicidios, un fuerte desbordamiento del crimen y la emergencia de nuevos actores, todo lo cual ha convertido a la región, y concretamente a los países del Triángulo Norte (Guatemala, El Salvador y Honduras), en uno de los lugares más peligrosos del mundo. ${ }^{6}$ Este escenario de

y 2012, Costa Rica registró un valor de 50.7; El Salvador 48.3; Guatemala 55.9; Honduras 57; Nicaragua 40.5; y, finalmente, México un 47.2 (idem:17).

${ }^{6}$ De acuerdo con diversos organismos, como la Organización Panamericana de la Salud (OPS) o la Oficina de Naciones Unidas contra la Droga y el Delito (UNODC, por sus siglas en inglés), el Triángulo Norte de Centroamérica constituye una de las regiones más violentas del mundo; con tasas de homicidios que oscilaron entre los 60 y 70 asesinatos por cada 100,000 habitantes. A partir de 2004, El Salvador se convirtió en el país más violento del mundo con una tasa de 65 homicidios; y en 2010 fue desplazado por Honduras, que tuvo una tasa de 82 homicidios en ese año, y 92 al año siguiente, perfilándose como el país más violento (Oficina de las Naciones 
violencia en Centroamérica constituye uno más de los factores que han incidido en la agudización y reconfiguración del fenómeno de la migración centroamericana en los últimos años. Así, tanto la migración de centroamericanos en tránsito por México, como el problema de la violencia, constituyen aspectos graves de la realidad de la región que tienen una de sus máximas expresiones en la frontera sur. No obstante, acciones $o$ iniciativas conjuntas encaminadas a hacerles frente, $o$ a solucionar de fondo los problemas estructurales y coyunturales que ocasionan la migración e inciden en el problema de la violencia, han figurado poco en las iniciativas bilaterales y prácticamente nada en los proyectos de cooperación entre México y Centroamérica, como el Proyecto Mesoamérica.

De aquí que el objetivo de este artículo sea presentar una visión crítica de la literatura oficial, cuyo contenido ha sido más bien propagandístico, con el fin de evaluar si los proyectos de cooperación y los acuerdos comerciales impulsados desde México han logrado contribuir a la solución de los problemas económicos y sociales de la región, los cuales son la raíz del fenómeno migratorio y de diversas expresiones de violencia, o si su desarrollo ha estado influido por los intereses de Estados Unidos y su política de seguridad nacional, que cuestionan el libre tránsito de personas y favorecen en cambio la creación de infraestructura para el intercambio de mercancías. Para ello, dedicaremos dos apartados a elaborar un recorrido por la historia de ambos fenómenos en las últimas décadas; después presentaremos la complejidad del entorno fronterizo al sur de México; luego daremos cuenta de los principales acuerdos y convenios entre México y Centroamérica; $y$, por último, dedicaremos una sección a analizar los proyectos de cooperación, en particular, el Proyecto Mesoamérica, destacando las diferencias entre sus objetivos, el discurso oficial y sus resultados concretos.

\section{Los rostros de la migración}

La crisis política centroamericana de fines de los años setenta y principios de los ochenta del siglo XX puso en evidencia la relevancia geopolítica Unidas contra la Droga y el Delito, 2014: 126; Oficina de las Naciones Unidas contra la Droga y el Delito, 2012: 12). 
del istmo y la consecuente necesidad de que México desempeñara un papel activo en el área, no sólo en función de sus propios intereses sino como un elemento que sirviera para ampliar su marco de negociación y le permitiera fortalecer su posición frente al gobierno de Washington. Cuando Ronald Reagan llegó a la presidencia de Estados Unidos en enero de 1981, la amenaza de intervención en el istmo centroamericano en el marco de la confrontación este-oeste incrementó la posibilidad de regionalización del conflicto. Con el argumento de la defensa de la seguridad nacional, la administración Reagan emprendió una Guerra de Baja Intensidad encaminada a dar marcha atrás a la revolución nicaragüense y a evitar que lo sucedido en Nicaragua se repitiera en El Salvador y Guatemala. De aquí que desarrollara una estrategia contrainsurgente encaminada a combatir y derrotar a los movimientos revolucionarios en la región. Para ello, se invirtió una gran cantidad de recursos destinados a reforzar a los ejércitos locales, al entrenamiento de soldados guatemaltecos y salvadoreños, al financiamiento de la Contra nicaragüense y a la construcción de bases militares y depósitos de armamentos en Honduras, todo lo cual condujo a un intenso proceso de militarización de la región centroamericana (Toussaint, 2017: 65-66).

Como resultado de las guerras civiles en Centroamérica, en los años ochenta tuvo lugar una fuerte oleada de migración de miles de personas que huyeron de la violencia política en sus respectivos países; en ese contexto, México se convirtió en un importante lugar de destino para la población desplazada y, de manera especial, brindó refugio a decenas de miles de guatemaltecos que huían de las masacres en su país y se asentaron en la frontera chiapaneca. Todo ello provocó que el gobierno de José López Portillo planteara como objetivo garantizar la estabilidad política y eliminar cualquier foco de tensión en su frontera sur que pudiera poner en riesgo su propia seguridad. Con la llegada de los refugiados guatemaltecos a Chiapas surgieron muchas voces en la propia administración gubernamental que veían este fenómeno como un riesgo y una amenaza para la seguridad nacional, principalmente en la Secretaría de Gobernación. Incluso se hablaba de un peligro inminente de que los movimientos revolucionarios centroamericanos se extendieran a México, especialmente si se tomaban en cuenta las 
condiciones de pobreza y conflictividad social del sureste mexicano que lo hacían mucho más vulnerable al contagio (Castillo, 2005a: 79; Castillo, 2005b: 1; Castillo, 2000: 141; Rodríguez Chávez, 2006: 2).

Este temor se incrementó debido a las frecuentes agresiones por parte del ejército guatemalteco en la década de los ochenta. Éstas consistían en operaciones militares en territorio mexicano para la persecución de guerrilleros guatemaltecos, por el grupo de fuerzas especiales conocido como los kaibiles, e incluían agresiones directas a refugiados a quienes se acusaba de dar apoyo a la guerrilla en Guatemala, llegando incluso a tener como víctimas a ciudadanos mexicanos. Estos ataques iban desde el robo de víveres y la destrucción de viviendas, hasta la desaparición y asesinato de algunos de sus habitantes. (Rodríguez de Ita, 2005: 115-116). ${ }^{7}$ Lo anterior coincidió con el incremento en el tráfico de estupefacientes, lo que propició que algunos sectores empezaran a establecer vínculos sin fundamento entre migración y narcotráfico, lo cual conllevó la presencia de unidades especializadas en el combate al narco en la frontera entre Chiapas y Guatemala (Castillo, 2005a: 80; Castillo, 200b: 5; Rodríguez de Ita, 2005: 133). De este modo, se produjo un proceso de militarización de la frontera sur en el que la presencia del ejército y operativos de control se convirtieron en acciones cotidianas en las rutas viales del estado de Chiapas y de la región fronteriza (Castillo, 2005a: 81; Castillo, 2000:141 y 146).

Para comprender la complejidad del fenómeno migratorio y su impacto en la frontera sur de México, es necesario hacer un breve recuento de lo sucedido en las últimas décadas. A lo largo de los años noventa, el flujo de población en tránsito en la frontera MéxicoGuatemala aumentó, con la consecuente preocupación por parte del gobierno de Estados Unidos que presionaba a su homólogo mexicano para que evitara el paso de esa corriente, que se había sumado a la migración irregular de mexicanos. Así, la migración de centroamericanos se convirtió en un tema de seguridad para México. Entre las medidas adoptadas para contener este flujo destaca el llamado

\footnotetext{
${ }^{7}$ Aunque los temores de contagio por parte de los revolucionarios centroamericanos nunca pudieron comprobarse, constituyeron un argumento de peso para la reubicación de una proporción importante de los refugiados asentados en Chiapas, los cuales fueron trasladados a Campeche y Quintana Roo entre 1983 y 1985.
} 
Plan Sur, que a inicios de la administración de Vicente Fox propuso reforzar los controles migratorios en la región comprendida entre el istmo de Tehuantepec y la frontera con Guatemala. Sin embargo, debido a la complejidad de la tarea de controlar el tránsito de personas en la frontera sur de México, a la escasez de recursos materiales, técnicos y humanos, y a la persistencia del flujo de migrantes en tránsito, el gobierno mexicano optó por hacer más eficientes los dispositivos de aseguramiento y deportación de los migrantes originarios de los países del istmo (Castillo y Toussaint, 2010: 281-282). ${ }^{8}$

A comienzos del siglo XXI, se registró una nueva oleada de migrantes centroamericanos, derivada de las condiciones de pobreza, desigualdad, marginalidad y exclusión imperantes; al mismo tiempo, fenómenos naturales que azotaron la región, como el terremoto de El Salvador (2001) y el huracán Stan (2005), incidieron en el incremento del éxodo centroamericano. Sin embargo, podemos afirmar que ha sido el crecimiento de la violencia social que vive la región en el contexto de posguerra, lo que se ha convertido en una de las causas fundamentales de esta fuerte oleada migratoria, en la que miles de centroamericanos se han visto forzados a desplazarse para huir de la violencia que afecta principalmente a los países del Triángulo Norte. Se estima que cada día alrededor de 200 o 300 migrantes centroamericanos cruzan la frontera sur y emprenden el viaje hacia el norte con rumbo a Estados Unidos; asimismo, se calcula que existe un contingente de más de 200,000 migrantes que cada año cruzan el territorio mexicano, e incluso de cerca de 400,000 en los años más críticos. ${ }^{9}$ En su mayoría, los migrantes centroamericanos son hombres; sin embargo, en años recientes se ha incrementado la presencia de mujeres y de menores no acompañados. ${ }^{10}$

\footnotetext{
${ }^{8}$ Uno de estos mecanismos fue el establecimiento de cuatro nuevos cruces fronterizos en 2003, con el objetivo de ordenar los flujos migratorios en la frontera sur y, al mismo tiempo, promover el desarrollo de las comunidades de la franja limítrofe. Aunado a lo anterior se pensó que, con la presencia de un mayor número de autoridades migratorias en la franja fronteriza, sería posible combatir el tráfico ilegal de personas y mercancías, lo que se había convertido ya en un problema de seguridad (Castillo y Toussaint, 2009: 84-85).

9 De acuerdo con datos del Instituto Nacional de Migración (INM), la migración centroamericana de tránsito irregular por México tuvo un máximo histórico en 2005 con aproximadamente 433,000 eventos (Rodríguez, Berumen y Ramos, 2011: 2).

${ }^{10}$ Para 2010, el porcentaje de mujeres fue de cerca de $14 \%$, y de niños fue de $7.3 \%$, más de la mitad de los cuales eran no acompańados (idem: 5).
} 
En este contexto, México dejó de ser un espacio de refugio para estos migrantes. La política del gobierno se ha dedicado a incrementar las medidas para contener la migración centroamericana, así como a endurecer el control y reforzar la presencia policial y militar en la frontera sur. Incluso muchos de ellos son retenidos por las autoridades mexicanas en las estaciones migratorias. De acuerdo con datos del Instituto Nacional de Migración, presentamos algunas cifras de migrantes centroamericanos indocumentados en tránsito por México, que fueron "asegurados" en dichas instalaciones:

Tabla 1. Aseguramientos de migrantes centroamericanos en estaciones migratorias, 2002-2015.

\begin{tabular}{|c|c|c|c|c|c|}
\hline Ańo/país & Guatemala & Honduras & El Salvador & Nicaragua & Total \\
\hline $\mathbf{2 0 0 2}$ & $\mathbf{6 7 , 3 3 6}$ & 41,801 & 20,800 & 1,609 & 131,546 \\
\hline $\mathbf{2 0 0 3}$ & 86,023 & 61,900 & 29,301 & 2,150 & 179,374 \\
\hline $\mathbf{2 0 0 4}$ & 94,404 & 72,684 & 34,572 & 2,453 & 204,113 \\
\hline $\mathbf{2 0 0 5}$ & 100,948 & 78,326 & 42,674 & 3,980 & 225,928 \\
\hline $\mathbf{2 0 0 6}$ & 84,523 & 58,001 & 27,287 & 3,590 & 173,401 \\
\hline $\mathbf{2 0 0 7}$ & 56,222 & 38,584 & 17,201 & 1,299 & 113,306 \\
\hline $\mathbf{2 0 0 8}$ & 42,689 & 30,696 & 13,576 & 1,605 & 88,566 \\
\hline $\mathbf{2 0 0 9}$ & 29,604 & 24,040 & 10,355 & 949 & 64,948 \\
\hline $\mathbf{2 0 1 0}$ & 29,154 & 23,788 & 10,573 & 833 & 64,348 \\
\hline $\mathbf{2 0 1 1}$ & 32,896 & 19,340 & 9,098 & 751 & 62,085 \\
\hline $\mathbf{2 0 1 2}$ & 40,060 & 28,892 & 12,397 & 683 & 82,032 \\
\hline $\mathbf{2 0 1 3}$ & 31,188 & 34,110 & 14,610 & 792 & 80,700 \\
\hline $\mathbf{2 0 1 4}$ & 47,794 & 47,521 & 23,131 & 1,180 & 119,626 \\
\hline $\mathbf{2 0 1 5}$ & 83,745 & 58,814 & 35,390 & 1,564 & 179,513 \\
\hline
\end{tabular}

Fuente: Elaboración propia con base en datos de Segob, Boletines estadísticos anuales. Disponibles en: http://www.politicamigratoria.gob.mx/es_mx/SEGOB/ Boletines_Estadisticos

Por último, es necesario destacar que el territorio mexicano se ha convertido en escenario de peligro, violencia y muerte. ${ }^{11}$ En su

\footnotetext{
${ }^{11}$ La masacre de 72 migrantes ocurrida en 2010 en San Fernando, Tamaulipas, constituye uno de los ejemplos más paradigmáticos.
} 
tránsito por México, los migrantes centroamericanos son cada vez más vulnerables a numerosos riesgos y peligros, entre ellos, asaltos, extorsiones, violaciones sexuales, abandono, secuestros, asesinatos y desapariciones forzadas. Asimismo, en su trayecto pueden ser reclutados por el crimen organizado, convertirse en víctimas de trata con fines de explotación sexual o laboral, o bien para tráfico de órganos y, en muchas ocasiones, llegar a sufrir mutilaciones o incluso la muerte al caer del tren. Estos peligros, maltratos y abusos a los que los migrantes indocumentados se enfrentan, son perpetrados por distintos actores, como bandas armadas, delincuentes, pandillas o maras, organizaciones criminales y, en algunos casos, por las propias autoridades estatales y de migración, la policía o el ejército.

\section{Escenarios de la violencia}

El fin de la guerra en Centroamérica no significó el cese de la violencia. A mediados de los años noventa, se observa un fuerte desbordamiento de violencia social y crimen en la región debido, sobre todo, a las limitaciones de los procesos de desmovilización derivados de los acuerdos de paz. Estos procesos no lograron insertar a la vida civil a los antiguos combatientes, dejaron circulando una enorme cantidad de armas de fuego remanentes de la guerra y no resolvieron los problemas estructurales que habían dado origen a los conflictos en el pasado. En este contexto, uno de los actores más visibles tanto en Centroamérica como en la frontera sur de México fueron las maras.

Sus orígenes se remontan a los años ochenta en la ciudad de Los Ángeles, California, cuando debido a la situación de pobreza, violencia y represión que se vivía en Centroamérica, miles de personas se vieron obligadas a emigrar de manera masiva a Estados Unidos. A partir de entonces, como un mecanismo de pertenencia y de defensa, numerosos jóvenes centroamericanos se integraron a pandillas en los guetos latinos de aquella ciudad, primero a las ya existentes, como el caso de la Eighteen Street Gang o Barrio 18, y luego crearon las propias, como la Mara Salvatrucha. Sin embargo, a principios de los años noventa, el gobierno estadunidense comenzó un proceso de deportación de extranjeros con antecedentes criminales, entre ellos, de jóvenes pandilleros 
centroamericanos. ${ }^{12} \mathrm{El}$ retorno de estos jóvenes a sus lugares de origen, se tradujo en la reproducción del modelo pandilleril angelino en el escenario centroamericano, y en la constitución de nuevas pandillas en los países del Triángulo Norte. La irrupción de las pandillas originarias de Los Ángeles en el istmo, transformó y reconfiguró la dinámica pandilleril de la región, y significó la emergencia de un fenómeno inédito, con características nuevas y expresiones particulares (Cruz y Portillo, 1998: 49-56).

Aunque algunos lo consideran un mal venido de fuera, es necesario aclarar que Centroamérica constituyó un terreno fértil para la gestación, propagación y agudización del fenómeno de las maras. En este sentido, sostenemos que su proliferación tiene su origen en las condiciones estructurales propias de la región (pobreza, desigualdad y exclusión social), así como en la precariedad, la marginación y la ausencia de oportunidades educativas y laborales que padecen los jóvenes. Asimismo, sus orígenes pueden rastrearse en la violencia del pasado reciente, en el legado autoritario y represivo de los regímenes dictatoriales, en la continuidad de la violencia armada por parte de diversos actores, en el vacío institucional, así como en la exacerbación de la cultura de la violencia y el deterioro del tejido social de la posguerra. (Castillo y Toussaint, 2009: 81; Alba y Kruijt, 2007: 491; Cruz, 2005: 1164).

Conviene señalar que, con el paso del tiempo, el fenómeno de las maras en Centroamérica se agravó significativamente. De ser en sus inicios grupos de control en un barrio que buscaban un marco de identidad y de defensa territorial, en los últimos ańos se convirtieron en uno de los actores más importantes y brutales de violencia en la región, con un perfil marcadamente criminal. Las pandillas son ahora

\footnotetext{
${ }^{12}$ En 1992, el Servicio de Inmigración y Naturalización de Estados Unidos creó una unidad antipandillas, cuyo objetivo era deportar a jóvenes extranjeros pertenecientes a estos grupos. Posteriormente, partir de 1996, el proceso de deportación se agudizó a consecuencia de la promulgación de la Ley de Reforma de la Inmigración Ilegal y de Responsabilidad del Inmigrante, estrategia que endureció las penas a la Ley de Inmigración, con lo cual los extranjeros sentenciados a un año o más de prisión serían repatriados a sus países. Como resultado de estas acciones, miles de pandilleros centroamericanos fueron deportados y retornaron a sus lugares de origen. De acuerdo a las estadísticas del Servicio de Inmigración y Naturalización de Estados Unidos, entre 1993 y 2005 Guatemala recibió 13,550 deportados con antecedentes penales, El Salvador 22,512 y Honduras 16,714 (Martín, Fernández y Villareal, 2007: 113-114).
} 
responsables de asesinatos, robos, extorsiones, reclutamientos forzados, violaciones y desapariciones, entre otros crímenes. Para muchos centroamericanos, la presencia y violencia de las pandillas ha significado la inmersión en una nueva guerra y en nuevos escenarios de terror. De acuerdo con fuentes policiales, en 2003 en Guatemala había 14,000 integrantes de pandillas, en Honduras 36,000, y en El Salvador 10,500 (Comisión de Jefes y Jefas de Policía de Centroamérica y el Caribe, 2003); actualmente, en este último país se estima que hay alrededor de 60,000 pandilleros (Ministerio de Justicia y Seguridad Pública, 2012).

A principios del siglo XXI, en los países del Triángulo Norte se generaron respuestas fuertemente represivas para hacer frente a la violencia de las maras. A partir de 2003, se impulsaron leyes antimaras y políticas de mano dura: la Operación Libertad o Plan Libertad, en Honduras; el Plan Escoba, en Guatemala; así como el Plan Mano Dura y Plan Súper Mano Dura, en El Salvador. Dichas estrategias coercitivas, entre otras cosas, criminalizaron la pertenencia a las pandillas e impulsaron fuertes operativos policiales, además de incrementar el accionar represivo de la policía, la remilitarización de la seguridad y la formación de comandos especiales de fuerzas policíacas y militares (Alba y Kruijt, 2007: 492; Arana, 2005: 121-122). Sin embargo, en lugar de ofrecer una solución, estas medidas agudizaron la problemática de las maras y engendraron una mayor violencia.

Como resultado de las políticas de mano dura, muchos miembros de pandillas dejaron sus lugares de origen huyendo de la represión y arribaron a México en los primeros años del siglo XXI. Desde entonces se empezó a observar la presencia de bandas de maras en la frontera de Chiapas y Guatemala, y más tarde se extendieron a la región del Soconusco, ${ }^{13}$ concentrando su espacio de acción alrededor de las vías del tren en el tramo de Ciudad Hidalgo a Tapachula. Uno de sus principales objetivos era asaltar a los migrantes, los cuales se encontraban indefensos frente a la acción de estas pandillas, que se convirtieron en una de las

${ }^{13}$ En el caso de la frontera sur de México, la presencia de las maras se debió a los desastres provocados por fenómenos naturales, como el huracán Mitch (1998), a los impactos de las políticas de mano dura aplicadas en los países del Triángulo Norte (2003), así como al aumento del narcotráfico y el crimen organizado en los ańos recientes (Ángeles, 2004: 95; Savenije, 2007: 637). 
principales amenazas para los migrantes indocumentados en tránsito. La presencia de las maras en la frontera sur incidió así en el incremento de las acciones delictivas en la zona (Ángeles, 2004: 95; Savenije, 2007: 639, 645-646; Benítez, 2009: 238; Castillo y Toussaint, 2009: 82). Conviene destacar también que la proliferación de las maras en la frontera sur se ha traducido en la estigmatización de los migrantes centroamericanos. De aquí que se les perciba como delincuentes, se refuerce la represión por parte de las autoridades y se incremente su vulnerabilidad. En suma, se ha desarrollado un proceso de criminalización de los migrantes y se ha utilizado el concepto de seguridad nacional como justificación para la adopción de políticas represivas y violatorias de los derechos humanos (Girardi, 2007: 154).

Por otra parte, a partir del gobierno de Felipe Calderón y tras el inicio de la llamada "guerra contra el narco", México ha sufrido en la última década una fuerte ola de violencia, cada vez más creciente, expresada en una agudización del problema de seguridad, en una mayor presencia y agravamiento del crimen organizado, en la militarización del país, en un fuerte incremento de los homicidios, como también en el desbordamiento de fenómenos como las masacres y las desapariciones forzadas, entre otros. ${ }^{14}$ De este modo, el territorio mexicano se ha convertido también en un escenario de violencia e inseguridad que afecta también a los migrantes en tránsito, aspectos que tienen una expresión particular en la frontera sur. En ella encontramos la presencia de diversos actores criminales que llevan a cabo actividades ilícitas como son el trasiego de drogas, el tráfico y la trata de personas. Además, se observa una débil acción del Estado, con un consecuente vacío de control en la región.

\footnotetext{
${ }^{14}$ De acuerdo con datos del Instituto Nacional de Estadística y Geografía (INEGI), durante el sexenio de Felipe Calderón ocurrieron cerca de 120,000 homicidios en el país, mientras que en la administración de Enrique Peña Nieto, concretamente en los primeros tres años, se contabilizaron alrededor de 65,800 homicidios. Una buena parte de estos asesinatos son adjudicados a la "guerra contra el narco". Buena parte de las víctimas se haya entre la población civil, a lo que el gobierno ha llamado "daños colaterales". Asimismo, el ascenso del número de muertos ha sido dramático: de 10,452 homicidios en 2006, se llegó a 27,213 en 2011. En términos de tasas de homicidios, se ha observado un fuerte incremento: de 9.3 homicidios por cada 100,000 habitantes en 2006, se ha llegado a 22.8 en 2011 (Oficina de las Naciones Unidas contra la Droga y el Delito, 2014: 126). Por otra parte, de acuerdo con el Registro Nacional de Datos de Personas Extraviadas o Desaparecidas (RNPED), de 2006 a 2016 se han reportado casi 30,000 casos de personas desaparecidas.
} 
En las zonas fronterizas donde existe una importante concentración de migrantes, el índice delictivo suele ser muy alto y, en muchas ocasiones, la población migrante se queda atrapada sin recursos para seguir su ruta de destino o regresar a su país. Así ha sucedido en la frontera sur de México, en donde la migración centroamericana ha sido vista como una amenaza, equiparándola con el narcotráfico, las pandillas, el tráfico de armas y el terrorismo. Sin embargo, esto no es así. Debemos destacar que la frontera sur, como se señaló antes, es más bien una región de riesgo para los migrantes centroamericanos y que se debe evitar a toda costa su criminalización (Castillo y Toussaint, 2010: 296-297; Armijo, 2015: 202-217). En suma, en el actual contexto, marcado por la agudización de los problemas estructurales, así como por la presencia de nuevos actores en México y Centroamérica, como las maras y el crimen organizado, tanto el fenómeno de la migración centroamericana como el de la violencia se han convertido en los dos temas neurálgicos de la región, en general, y de la frontera sur, en particular.

\section{Una frontera compleja}

El cruce de la frontera sur de México implica un riesgo, especialmente para los migrantes indocumentados que buscan los caminos de más difícil acceso para evitar ser detectados por las autoridades migratorias mexicanas. Ello se debe, además, a su complicada topografía, sus ríos caudalosos, la espesura de su selva y la peligrosidad de su fauna, que hacen del cruce un riesgo permanente (Encuesta, 2006: 23). En los últimos años, la migración internacional en la frontera ChiapasGuatemala se ha vuelto de alto riesgo para los migrantes provenientes de Guatemala, El Salvador, Honduras y Nicaragua, quienes al transitar por la costa chiapaneca en la región del Soconusco, se exponen a todo tipo de amenazas, accidentes ${ }^{15} \mathrm{y}$ violaciones a los derechos humanos. Todos estos obstáculos y riesgos afectan directamente el proyecto de migrar pues lo retrasan o lo cancelan definitivamente (Ruiz, 2001:8, 16-17, 30-31; Díaz y Kuhner, 2007: 5).

\footnotetext{
${ }^{15}$ Los migrantes pueden morir de insolación o deshidratación, pueden ser atropellados en las carreteras o tener accidentes en automóviles o autobuses, destacando más las caídas del tren carguero las cuales provocan lesiones, amputaciones o incluso la muerte (Vericat, 2007: 47-51 y 65-69; Ruiz, 2001: 17-19).
} 
Uno de los mayores riesgos para los migrantes son las violaciones a los derechos humanos por parte, tanto de autoridades migratorias, municipales y locales, como por parte de delincuentes individuales o bandas organizadas. A medida que transitan por lugares despoblados, sin control ni vigilancia, se registra una mayor cantidad de asaltos y agresiones (Ruiz, 2001:17; Castillo y Herrera, 2006: 22; Castillo, 2003: 8). A raíz del endurecimiento de las leyes migratorias, han aumentado los riesgos a los que están expuestos los migrantes. De aquí que los flujos migratorios tiendan a dirigirse hacia puntos donde no hay controles, lo que los ha conducido a la utilización de rutas mucho más peligrosas. (Castillo, 2003: 7-8; Díaz y Kuhner, 2007: 5; Dardón, 2002: 299).

A partir de la administración de Vicente Fox se hizo explícita la intención de llegar a un acuerdo migratorio con Estados Unidos que permitiría abordar el fenómeno de manera integral. No obstante, los acontecimientos del 11 de septiembre de 2001 interrumpieron el diálogo y pusieron fin a todas las expectativas que se habían generado. A partir de entonces, la política migratoria del gobierno estadunidense sufrió un viraje radical y empezó a tener como base los criterios de seguridad nacional. De manera paralela, el gobierno mexicano comenzó a endurecer su política hacia la migración en la frontera sur, con la intención explícita de impedir que los migrantes irregulares llegaran a la frontera norte de México. Fue entonces cuando el gobierno mexicano anunció la puesta en marcha del llamado Plan Sur, como forma de control y regulación de la migración en la región fronteriza, desde el istmo de Tehuantepec hasta los límites con Guatemala (Castillo, 2005 a: 83; Castillo, 2006: 3; Castillo, 2003: 9). Sin embargo, el Plan Sur demostró ser una medida inviable debido a la gran cantidad de recursos materiales, técnicos y humanos necesarios para su aplicación y a la falta de confianza en que por este medio se podrían contener los flujos migratorios indocumentados (Casillas, 2006:8).

Así, encontramos que la región fue identificada por los militares estadunidenses como un flanco vulnerable para su seguridad (Benítez, 2009: 234-235). De aquí el interés del gobierno de Washington por reforzar la vigilancia y sellar la frontera sur de México, con la finalidad 
de evitar que los migrantes centroamericanos llegaran a Estados Unidos. (Toussaint y Castillo, 2009: 81). Dicha frontera se convirtió en un territorio estratégico para la defensa de la seguridad estadunidense y fue considerada parte fundamental de su perímetro de seguridad. ${ }^{16} \mathrm{~A}$ partir del 11 de septiembre de 2001, la seguridad se vinculó cada vez más a los escenarios fronterizos, por lo que a los obstáculos físicos y a los riesgos que enfrentan los migrantes, se sumó un complejo sistema de vigilancia, policíaca y militar, dejando de lado cualquier tipo de política humanitaria hacia ellos (Iruegas, 2007). Todas estas acciones son evidencia de que hasta ahora sólo se ha considerado una faceta del fenómeno migratorio y se han dejado de lado sus causas estructurales, que tienen que ver con las necesidades no satisfechas de la población en sus lugares de origen (Castillo, 2005 a: 84).

En este contexto podemos ubicar también a la Iniciativa Mérida, derivada de la preocupación de los gobiernos de México y Estados Unidos por combatir el crimen organizado y el narcotráfico (Rico, 2008: 3; Gómez, 2007). Esta iniciativa surgió a partir de la visita del presidente George Bush a Guatemala y México en marzo de 2007, en la cual se constató que el problema de seguridad había alcanzado dimensiones críticas en ambos países, que lo habían convertido en un asunto regional, por lo que era necesario la formulación de estrategias conjuntas basadas en la cooperación, la reciprocidad y la responsabilidad compartida. Se argumentaba que los gobiernos latinoamericanos carecen de instrumentos eficaces para enfrentar al crimen organizado, porque éste aprovecha los vacíos e inconsistencias de los diversos sistemas judiciales, así como por la falta de control de las fronteras físicas, como la que separa México de Guatemala. ${ }^{17}$ Por ello, la Iniciativa Mérida planteaba que Washington otorgara recursos a México y a Centroamérica para prevenir el ingreso y

\footnotetext{
${ }^{16}$ La conveniencia para el gobierno de Washington de la creación de un Perímetro de Seguridad de América del Norte se ha visto expresada en la creación del esquema de cooperación con México y Canadá: la Asociación para la Seguridad y la Prosperidad de América del Norte (ASPAN).

${ }^{17}$ El desarrollo de una capacidad real de vigilancia implica una gestión eficiente de las fronteras marítimas y terrestres, así como de los puertos y aeropuertos, de forma tal que el control de los flujos indeseados no obstaculice el de los que son legítimos y cada vez más importantes para la economía del país (Rico, 2008: 6).
} 
tránsito de drogas, armas, personas y recursos financieros a través de la región con rumbo hacia Estados Unidos (Bailey, 2008: 1; Benítez, 2007: 1-2, 4; Rico, 2008: 7). ${ }^{18}$

Sin embargo, las cosas no son tan sencillas. Uno de los problemas radica en que esta iniciativa implica que el gobierno mexicano se subordine a los dictados del norte, en un esfuerzo por reforzar la vigilancia y sellar la frontera sur para evitar que los migrantes centroamericanos lleguen a Estados Unidos. Se trata de que, a los obstáculos físicos y los riesgos propios del viaje, se sume todo un sistema de vigilancia tecnificada, policíaca y militar, dejando de lado cualquier tipo de actitud humanitaria hacia los migrantes centroamericanos, con la justificación de proteger el territorio nacional y frenar su paso por México (Iruegas, 2007).

Por último, cabe destacar que al problema de las maras y el narcotráfico se debe agregar la proliferación en Centroamérica y México de un nuevo tipo de organización criminal, conformada por bandas especializadas en robos y secuestros, equipadas con armas sofisticadas, formadas por ex oficiales del ejército o de la policía (Alba y Kruijt, 2007:492). De aquí que, con el objetivo de combatir el terrorismo, el crimen organizado y el tráfico ilícito de mercancías, México, Guatemala y Belice crearan en 2002 un mecanismo denominado Grupo de Alto Nivel sobre Seguridad Fronteriza (GANSEF). Éste se reunió por primera vez en marzo de 2003 y estableció como prioridad los conflictos fronterizos vinculados a la migración, el terrorismo internacional, el crimen organizado y la seguridad (Castillo y Toussaint, 2009: 84). A partir de entonces, el GANSEF tuvo reuniones periódicas para examinar los avances en los mecanismos de cooperación para la seguridad en el área fronteriza entre los tres países.

Sin embargo, sus resultados fueron muy limitados. La inseguridad en México se incrementó y continuó la penetración de bandas de narcotraficantes a través de las fronteras terrestres y marítimas. De aquí

${ }^{18}$ La Iniciativa incluye la dotación de equipo de inspección, scanners de ion, unidades caninas de intercepción, tecnologías de comunicación, asesoría técnica y entrenamiento para las instituciones de justicia, programas de protección de testigos, helicópteros y aviones de vigilancia, todo ello para lograr una rápida intercepción. El programa no incluiría ni la presencia en México de efectivos militares estadunidenses, ni la participación de representantes de las agencias civiles de ese país en las funciones operativas (Benítez, 2007:4; Rico, 2008:11-12). 
que las autoridades mexicanas consideraran necesario reforzar la vigilancia en la frontera y tomar otro tipo de medidas (Rico, 2008: 8; Castillo y Toussaint, 2009: 85). Dentro de las estrategias de cooperación, se propuso consolidar un programa que sustituyera al Plan Puebla Panamá y se enfocara a promover el desarrollo de la región mesoamericana. En este contexto, partiremos de analizar tanto el papel de las iniciativas bilaterales - firma de tratados y convenios- como de los esfuerzos regionales, siendo el más emblemático el Proyecto Mesoamérica. A partir de este análisis podremos evaluar si se han encaminado a la resolución de estos dos aspectos, tan importantes para los habitantes de la frontera sur de México y de los países del istmo centroamericano, o si han estado más bien guiados por preocupaciones que responden a otro tipo de intereses.

\section{México frente a Centroamérica}

A lo largo del siglo XX, los vínculos entre México y las repúblicas centroamericanas se enmarcaron fundamentalmente en el campo de la cooperación educativa y cultural, y no tuvieron mayores repercusiones de índole social. ${ }^{19}$ Como consecuencia de la política activa de México hacia Centroamérica en los años ochenta, en ese periodo se firmaron tres convenios más de cooperación: uno de intercambio cultural con Belice (1982) y dos más de cooperación turística, primero con Costa Rica (1980) y luego con Guatemala (1987). ${ }^{20}$ Destaca en esos años la firma de un Acuerdo de Cooperación económica, científico-técnica, cultural y educativa entre México y Nicaragua (1983), el cual constituyó una clara forma de apoyo hacia el gobierno sandinista establecido después

\footnotetext{
${ }^{19}$ El primer convenio de esta índole se firmó con Guatemala en 1966, derivado de la visita del presidente Gustavo Díaz Ordaz a la región, y tenía como objetivo contribuir al conocimiento de las respectivas culturas, costumbres y actividades en el campo de las humanidades, las artes, las ciencias y la tecnología. En 1975, se firmó con Guatemala un convenio relativo a la protección y restitución de monumentos arqueológicos, artísticos e históricos, para estimular el estudio y el conocimiento recíproco de los valores arqueológicos, artísticos e históricos de ambos países, y establecer normas para la protección de bienes culturales comunes (www.sre. gob.mx/tratados).

${ }^{20}$ El primero tenía como objetivo estrechar los vínculos de amistad entre ambos países y fomentar la colaboración en el campo de la cultura, la educación, las artes, las humanidades y el deporte. Los acuerdos de cooperación turística buscaban acercar a los países a través del fomento de las relaciones turísticas y la cooperación de sus organismos especializados en la materia (ibidem).
} 
de la caída de Anastasio Somoza en 1979, y que estaba destinado a apoyar los proyectos de desarrollo en ese país. ${ }^{21}$

Con el impulso a la política de cooperación de México hacia la región en los años noventa, a partir de la creación de la Comisión Mexicana de Cooperación con Centroamérica, y en el marco de los acuerdos derivados de las reuniones de Tuxtla, se firmaron una serie de convenios y acuerdos bilaterales con los países centroamericanos: seis de cooperación técnica y científica, con Belice (1995), El Salvador (1995), Honduras (1995), Nicaragua (1995), Costa Rica (1995) y Guatemala (1998); cuatro de cooperación educativa y cultural, con Costa Rica (1995), El Salvador (1997), Honduras (1998) y Nicaragua (2000); otros tres relativos a la protección y restitución de monumentos arqueológicos, artísticos e históricos, de los cuales uno fue firmado con El Salvador (1990) y dos con Belice (1990 y 1991); y, por último, cuatro más, suscritos con Belice (1990), Nicaragua (1990), Honduras (1990) y El Salvador (1990), en materia de cooperación turística. ${ }^{22}$ Pero ninguno de ellos tuvo que ver ni con el fenómeno migratorio ni con los problemas de inseguridad y violencia en la frontera sur.

A partir de una somera revisión de los acuerdos y convenios firmados por México con los países centroamericanos en las últimas tres décadas, tanto a nivel bilateral como en el ámbito regional, observamos que sus alcances son bastante limitados y que sólo algunos de ellos han tenido que ver con aspectos significativos de las relaciones regionales: tratados referentes al entorno fronterizo de México con Guatemala y Belice, que abarcan asuntos de límites y aguas, conservación de recursos naturales, protección y mejoramiento del ambiente, cooperación para la prevención y atención en casos de desastres producidos por fenómenos naturales y cuestiones sanitarias, entre otros; ${ }^{23}$ tratados que rebasan el ámbito de la frontera sur de México y se refieren a un tema que tiene efectos tanto en los países del istmo centroamericano como en el resto de América Latina: el narcotráfico y la farmacodependencia; ${ }^{24}$ y

\footnotetext{
${ }^{21}$ Ibidem.

22 (Ibidem).

${ }^{23}$ Sobre estos temas se firmaron con Guatemala un Convenio (1987), dos Acuerdos (1987 y 2003) y un Tratado (1990); mientras que con Belice se firmó un Convenio (1991) (ibidem).

${ }^{24}$ Con Guatemala (1989), con Costa Rica (1989), con Belice (1990), con Honduras (1990),
} 
tratados relacionados con el problema de la extradición y la asistencia jurídica mutua en materia penal, con el fin de cooperar de manera más estrecha en la lucha contra la delincuencia y el crimen organizado, para lo cual se firmaron tratados con todos los países centroamericanos, a excepción de Honduras. ${ }^{25}$

Sin embargo, en consonancia con los objetivos de los proyectos de cooperación internacional para el desarrollo, promovidos por iniciativas como el Plan Puebla Panamá y el Proyecto Mesoamérica, a los acuerdos a los que el gobierno le ha dado mayor importancia en los últimos años es a los de libre comercio entre México y los países centroamericanos. Así, en los años noventa, se impulsó la firma de tres tratados de libre comercio: uno con Costa Rica, uno más con Nicaragua y otro con los países del Triángulo Norte. El objetivo era crear una zona de libre comercio y favorecer el proceso de integración regional entre México y Centroamérica, estimular la expansión y diversificación del comercio de bienes y servicios, facilitar la circulación de los mismos, eliminar las barreras al comercio, promover condiciones de competencia leal, suprimir aranceles, adoptar medidas sanitarias y fitosanitarias, proteger y hacer valer los derechos de propiedad intelectual, incrementar las oportunidades de inversión, así como proteger y dar seguridad jurídica a los inversionistas. En suma, la intención era establecer lineamientos para la cooperación a nivel bilateral, regional y multilateral que favorecieran en gran medida a los inversionistas privados. ${ }^{26}$

Los tratados de libre comercio con Costa Rica (1994) y Nicaragua (1997) tuvieron como consecuencia una mayor concentración de exportaciones costarricenses a México en el rubro de componentes de computadora y aceite de palma en bruto; crecimiento de la inversión

con Nicaragua (1992) y con El Salvador (1993) (ibidem).

${ }^{25}$ Con Belice (1988), con Costa Rica (1989), con Nicaragua (1993), con Guatemala (1996 y 1997), con El Salvador (1997) (ibidem).

${ }^{26}$ Las negociaciones no fueron fáciles debido a que algunos sectores productivos centroamericanos se mostraban temerosos de la liberalización comercial con México, ya fuera por la posibilidad de una llegada masiva de productos mexicanos a la región, por las dificultades para ingresar al mercado mexicano o porque México no aceptara la entrada de productos manufacturados. Por su parte, los empresarios mexicanos, se interesaron en este acercamiento debido a que, desde su perspectiva, les daría amplias oportunidades para colocarse en sectores como las telecomunicaciones, el turismo, la construcción y los servicios (ibidem). 
mexicana en Costa Rica en términos absolutos; concentración de la inversión mexicana en la industria costarricense de alimentos, comercio, servicios y construcción; incremento del intercambio comercial entre México y Costa Rica; incremento de la inversión tica en México; aumento del volumen total de las exportaciones mexicanas a Nicaragua; e incremento del total de mercancías exportadas de Nicaragua a México (Orduña, 2008: 263-266).

Por otra parte, a principios de 1996, México inició las negociaciones para la firma del Tratado de Libre Comercio con los países del Triángulo Norte, las cuales culminaron en el año 2000. El objetivo del tratado consistía en ampliar y normar sus relaciones comerciales, incrementar las oportunidades de mercado para la industria, el agro y el comercio, beneficiar a los consumidores con más y mejores productos, atraer inversión extranjera que ayudara a generar empleos, y contar con un mecanismo de solución de controversias comerciales (Aguilar, 2003). Como consecuencia, los países del Triángulo Norte se convirtieron en el principal mercado de México en América Latina. ${ }^{27}$ Sin embargo, en términos relativos, el comercio entre México y Centroamérica es de una muy escasa relevancia, incluso después de la firma de estos Tratados. No sólo contrasta con las abrumadoras cifras del comercio de México con América del Norte, especialmente con Estados Unidos, sino que existen otras varias regiones del mundo que se encuentran por encima de los países centroamericanos en cuanto a las cifras de sus vínculos comerciales con México.

\section{Los límites de la cooperación}

El Proyecto de Integración y Desarrollo de Mesoamérica se constituyó en junio de 2008 en el marco de la X Cumbre de Jefes de Estado y de Gobierno del Mecanismo de Diálogo y Concertación de Tuxtla, a iniciativa del gobierno de Felipe Calderón. Ante las deficiencias del Plan Puebla Panamá, ${ }^{28}$ aunado a las constantes críticas de la sociedad

\footnotetext{
${ }^{27}$ Las ventas de México a esta región superaron a la suma de las exportaciones de productos mexicanos a Brasil, Argentina y Chile.

${ }^{28}$ En una primera evaluación, se consideró que el PPP había permitido avanzar en la construcción de plataformas de infraestructura eléctrica, telecomunicaciones y transporte, pero que no había permitido crear un espacio articulador de los esfuerzos de cooperación regional. Proyecto Mesoamérica, http://proyectomesoamerica.org/joomla/
} 
civil, el gobierno mexicano planteó la necesidad de llevar a cabo un proceso de renovación, fortalecimiento y reestructuración de este mecanismo de cooperación. Bajo nuevos esquemas de organización y trabajo, se buscaba consolidar, redefinir y dar continuidad a las acciones y proyectos de integración y desarrollo trazados, cuyo impulso incidiera en la prosperidad de los habitantes de Mesoamérica y tuviera un impacto tanto económico como social en la región (Declaración de Villahermosa, 2008). Es así como surgió el Proyecto Mesoamérica, como una nueva estrategia de cooperación, integración y desarrollo, el cual estaría integrado tanto por los antiguos miembros -México, Belice, Guatemala, El Salvador, Honduras, Nicaragua, Costa Rica y Panamá-, como por Colombia y República Dominicana, que se sumaron como nuevos participantes.

La transformación del Plan Puebla Panamá en Proyecto Mesoamérica implicó un proceso de reestructuración que conllevó un cambio en la dinámica de trabajo. En primer lugar, se sustituyó el esquema de cooperación original que incluía ocho iniciativas mesoamericanas bajo la responsabilidad de un país, ${ }^{29}$ por un modelo más pragmático, de atención focalizada y de conducción de programas y proyectos específicos, con planes anuales; en segundo lugar, se transformó la estructura organizacional, que contempló el fortalecimiento de las instancias ya establecidas y la vinculación con otros actores regionales. Se pensaba que dicha reestructuración permitiría evolucionar hacia un programa de integración y desarrollo que, entre otras cosas, definiría y consolidaría proyectos económicos en materia comercial, de energía y de infraestructura, e incorporaría programas de alto impacto social en materia de salud, vivienda, medio ambiente y desastres (Secretaría de Relaciones Exteriores, 2012: 11-12).

Los proyectos emblemáticos que se definieron en el marco de la reestructuración fueron los siguientes: Sistema de Interconexión Eléctrica para América Central (SIEPAC), que incluía la interconexión entre México y Guatemala, y entre Panamá y Colombia; Telecomunicaciones,

\footnotetext{
${ }^{29}$ Desarrollo sustentable (Nicaragua); Desarrollo humano (México); Prevención y atención a desastres naturales (sic) (Panamá); Turismo (Belice); Facilitación del intercambio comercial (Honduras); Integración vial y transporte (Costa Rica); Desarrollo e interconexión energética (Guatemala); Integración de los servicios de telecomunicaciones (El Salvador) (Serna, 2008: 222).
} 
que abarcaba la Autopista Mesoamericana de la Información (AMI); Transporte, cuyo objetivo era la creación de una Red Internacional de Carreteras Mesoamericanas (RICAM); Facilitación Comercial y Competitividad, por medio de la creación de un Procedimiento Mesoamericano para el Tránsito Internacional de Mercancías (TIM); Sistema Mesoamericano de Salud Pública (SMSP); Programa para el Desarrollo de Vivienda Social en Centroamérica (PDVSCA); Estrategia Mesoamericana de Sustentabilidad Ambiental (EMSA); y el Sistema Mesoamericano de Información Territorial (SMIT) para la reducción de riesgos y desastres en la región. Entre los acuerdos establecidos en la "Declaración de Villahermosa", firmada por los Jefes de Estado y de Gobierno, destacaron la búsqueda del incremento de los apoyos políticos, técnicos y financieros para alcanzar las metas establecidas para cada uno de dichos proyectos, así como la aplicación de esquemas de asociación público-privada para potenciar la ejecución de los mismos y fomentar la inversión (ídem: 12; Declaración de Villahermosa, 2008).

Frente a un contexto económico y social marcado por bajos índices de desarrollo y por la presencia de profundos problemas estructurales en la región, el Proyecto Mesoamérica se concibió dentro de la propia Secretaría de Relaciones Exteriores como un nuevo mecanismo de cooperación entre los países, que permitiría reconfigurar y consolidar la cooperación entre México y Centroamérica, que traería consigo la implementación de distintos proyectos de desarrollo e infraestructura, con el objetivo de hacer frente a los retos económicos y sociales comunes, al tiempo que incidiría en un mayor desarrollo y prosperidad, así como en el mejoramiento de las condiciones de vida de la población (Secretaría de Relaciones Exteriores, 2012: 7-8).

Sin embargo, aunque se recalcó el impacto económico y social que tendrían dichos programas, lo cierto es que el Proyecto Mesoamérica no tuvo un efecto significativo en el desarrollo social y humano en la región, como tampoco en la resolución de fondo de los principales problemas estructurales ni en el mejoramiento de las condiciones de vida de sus habitantes. Más bien, el Proyecto Mesoamérica centró sus horizontes en el desarrollo económico en términos de competitividad y productividad, poniendo el énfasis en la implementación de estrategias 
encaminadas a incrementar los intercambios económicos, comerciales y de inversión entre los países de la región, a garantizar el libre tránsito de mercancías, a contribuir al fortalecimiento de los tratados de libre comercio, a impulsar la construcción de infraestructura en función de necesidades meramente económicas, así como a favorecer la entrada de capitales privados para la ejecución de los distintos proyectos.

Los proyectos impulsados se perfilarían en torno a dos ejes: por una parte el eje económico, que consolidaría los programas desarrollados en el pasado, y que continuaría con proyectos que girarían en torno a las materias de comercio, energía, infraestructura, transporte, eléctricidad y telecomunicaciones; $y$, por otra parte, el eje social, que debería incorporar proyectos de alto impacto en las áreas de salud, vivienda y medio ambiente. En el discurso, el Proyecto Mesoamérica ofrecía impulsar el bienestar y el desarrollo económico y social expresado, fundamentalmente, en el fortalecimiento del mercado intrarregional, el ensanchamiento de la infraestructura, la conservación del medio ambiente y el acceso universal a servicios básicos como la vivienda y la salud (Comisión Económica para América Latina y el Caribe, 2015: 9 y 18).

Sin embargo, los resultados de los proyectos no fueron contundentes $y$ no incidieron en un mayor desarrollo, como tampoco en un mejoramiento sustantivo de las condiciones de vida en la región. Como se dijo antes, el Proyecto Mesoamérica centró la mirada en aspectos de competitividad, productividad, fortalecimiento comercial, facilitación del flujo de mercancías e inversión de capitales privados, ignorando tanto los problemas estructurales de la región — pobreza, desigualdad, marginación y exclusión-, como las condiciones que los generan y sus consecuencias sociales. En este sentido, los programas promovidos por el Proyecto Mesoamérica más bien respondieron a las necesidades del capital trasnacional, de la economía de mercado y del contexto neoliberal.

Analicemos ahora la manera en que el Proyecto Mesoamérica abordó los distintos problemas, tanto del eje económico - comercio, infraestructura, energía-, como del eje social —salud, vivienda y medio ambiente:

1. En lo que respecta a la materia de comercio, el Proyecto Mesoamérica buscó la implementación de mecanismos que fortalecieran el 
mercado intrarregional y el intercambio comercial, y que facilitaran el tránsito de mercancías entre los países de la región y en la frontera sur de México, tales como la modernización de aduanas y pasos fronterizos, así como la rehabilitación y mantenimiento de los puentes internacionales (Secretaría de Relaciones Exteriores, 2012: 25-29). Buscó, además, aumentar la productividad y la competitividad de los países, con el objetivo de incentivar la inversión extranjera directa en cada uno de ellos. Asimismo, resolvió establecer un sistema de sanidad que facilitara los procesos de inspección y certificación, contribuyendo a mejorar el intercambio de productos agropecuarios.

2. El Proyecto Mesoamérica se propuso también desarrollar y consolidar la infraestructura de la región, principalmente la de transportes, ${ }^{30}$ así como la eléctrica ${ }^{31}$ y de telecomunicaciones. ${ }^{32}$ El principal objetivo era aumentar la conectividad de las redes de transporte de los distintos países a través de la inversión en infraestructura, principalmente la carretera (idem: 18-19). Se daría especial atención a la rehabilitación y ampliación de los Corredores Viales Pacífico, Atlántico, Turístico del Caribe y Corredores Interoceánicos (Declaración de Villahermosa, 2008). Esta iniciativa se impulsó, fundamentalmente, para asegurar y facilitar el tránsito de mercancías entre los países centroamericanos. De igual forma, sentaba las bases para la inversión privada en la construcción de dichos proyectos de infraestructura.

3. En materia de energía, el Proyecto Mesoamérica tuvo como objetivo impulsar un Sistema de Interconexión Eléctrica; al mismo tiempo, aprovechando la red de infraestructura eléctrica, buscó promover la instalación de fibra óptica para facilitar la interconexión en telecomunicaciones e impulsar el mercado regional en este ámbito (Secretaría de Relaciones Exteriores, 2012: 21-25). Asimismo,

\footnotetext{
${ }^{30}$ Además de la creación de una red carretera regional, se buscaba desarrollar proyectos complementarios en materia marítimo-portuaria y aeroportuaria (Declaración de Villahermosa, 2008).

${ }^{31}$ En este aspecto se contemplaban también la producción de biocombustibles, los programas de electrificación rural en Guatemala y Honduras, y los proyectos de generación y refuerzo de subestaciones y líneas de transmisión nacional en El Salvador, con el fin de fortalecer las capacidades nacionales de generación eléctrica (ibidem).

${ }^{32}$ El objetivo era la instalación de banda ancha con inversión pública y privada y la integración regional de servicios de telecomunicaciones (ibidem).
} 
pretendió contribuir al desarrollo de fuentes de energía renovables. Por supuesto, estos proyectos tenían como telón de fondo promover la apertura a la inversión de capital privado.

4. En el tema de salud, el Proyecto Mesoamérica propuso respaldar el desarrollo de un Sistema Mesoamericano de Salud Pública, a través del cual se buscaría disminuir las brechas de desigualdad que padecen los países en materia de salud, y atender de manera conjunta los principales problemas que en este ámbito aquejan a la región. En este sentido, se buscaría ampliar la cobertura de los servicios de salud en los distintos países; atender a las comunidades más pobres y combatir enfermedades asociadas a la pobreza, como aquellas de origen infeccioso o la mortalidad materna e infantil y, además, hacer frente a otras enfermedades como el dengue y la malaria; $y$, finalmente, fortalecer acciones de seguridad alimentaria y nutricional para erradicar el hambre (idem: 29-31). En el impulso de este proyecto, también se resolvió abrir las puertas al capital privado a través de iniciativas de asociación público-privadas para la inversión en materia de salud.

5. En cuanto al tema de la vivienda, el Proyecto Mesoamérica buscó implementar un Programa para el Desarrollo de Vivienda Social en Centroamérica. La falta de viviendas dignas para vastos sectores de la población y la existencia de barrios marginales poblados de tugurios constituyen uno de los problemas más apremiantes de la región. En este sentido, el objetivo era desarrollar y fortalecer un mercado de financiamiento hipotecario sostenible con el otorgamiento de créditos para el acceso a la vivienda (ídem: 32). Sin embargo, no se buscó resolver de fondo este problema; es decir, nuevamente observamos que no se atacaron las causas estructurales de pobreza, desigualdad, exclusión y marginación que lo ocasionan.

6. Por último, respecto al medio ambiente, el Proyecto Mesoamérica buscó respaldar una Estrategia Mesoamericana de Sustentabilidad Ambiental, a través de la cual se impulsaran programas de desarrollo sostenible, de preservación del capital cultural, así como acciones de protección de los recursos naturales y los ecosistemas de la región. Asimismo, se implementarían distintas estrategias para hacer frente a desafíos como el cambio climático y ejecutar acciones de desarrollo 
para reducir la vulnerabilidad y el riesgo, derivados de los desastres (idem: 33-34)..$^{33}$

A partir de lo anterior podemos observar que, si bien en el discurso del Proyecto Mesoamérica el objetivo fundamental era la ejecución de proyectos para el desarrollo económico y social de los países del istmo centroamericano y el mejoramiento de las condiciones de vida de sus habitantes, lo cierto es que las necesidades socioeconómicas más apremiantes fueron desdibujadas del horizonte de prioridades de este proyecto de cooperación y, como se dijo antes, las posibles estrategias encaminadas a resolver de fondo los problemas estructurales de la región estuvieron ausentes en el diseño de los programas concretos.

Es evidente que, tanto los proyectos del eje económico como los del eje social, no se encaminaron al logro de un verdadero desarrollo social y humano en la región, y tampoco se tradujeron en el mejoramiento de las condiciones de existencia de quienes la habitan. Más que impulsar el desarrollo económico integral en beneficio de la población, el primer eje de proyectos estuvo dedicado a lograr una mayor competitividad y productividad, facilitar el intercambio comercial y el tránsito de mercancías en beneficio de grandes capitales trasnacionales, así como ofrecer las condiciones óptimas para la inversión privada. Por su parte, aunque el segundo eje de proyectos abordó problemas sociales importantes, como la falta y precariedad de la vivienda, y la mala cobertura de los servicios de salud, no se encaminó a lograr transformaciones sociales significativas, ni a solucionar de fondo las condiciones estructurales que históricamente han generado dichos problemas. De igual forma, en materia de medio ambiente, las acciones impulsadas tuvieron como consecuencia la ejecución de megaproyectos que redundaron en la explotación de los recursos naturales estratégicos de la región, con importantes afectaciones y costos sociales para las comunidades.

En las siguientes tablas presentamos los índices de pobreza, indigencia, desigualdad y desarrollo humano, tanto en México como en los países centroamericanos, entre 2006 y 2014. En ellas podemos observar que en términos de pobreza e indigencia las cifras se han mantenido estables y, en algunos casos, incluso se han incrementado. De la misma

${ }^{33}$ Los temas prioritarios acordados fueron biodiversidad y bosques, cambio climático y competitividad sostenible (Declaración de Villahermosa, 2008). 
manera, los indicadores de desigualdad no han experimentado cambios sustanciales y las cifras no presentan mayores variaciones. Por último, en lo que se refiere a los indicadores de desarrollo humano, si bien en la mayoría de los casos se observa un ligero repunte, se trata en realidad de porcentajes menores que no dan cuenta de una mejoría sustancial en las condiciones de vida de la población.

Tabla 2. Porcentaje de la población en situación de pobreza, 2006-2014.

\begin{tabular}{|l|c|c|c|c|c|c|c|c|c|}
\hline País/ańo & 2006 & 2007 & 2008 & 2009 & 2010 & 2011 & 2012 & 2013 & 2014 \\
\hline México & 42.9 & - & 47.8 & - & 51.1 & - & 52.3 & - & 53.2 \\
\hline Guatemala & 51.0 & - & - & - & - & 53.70 & - & - & - \\
\hline Honduras & 59.9 & 58.2 & 59.2 & 58.8 & 60.0 & 61.93 & 66.5 & 64.5 & 62.8 \\
\hline El Salvador & 30.7 & 34.6 & 40.0 & 37.8 & 36.5 & 40.60 & 34.5 & 29.6 & 31.8 \\
\hline Nicaragua & - & - & - & 42.5 & - & - & - & - & - \\
\hline Costa Rica & 20.2 & 16.7 & 17.7 & 18.5 & 21.2 & 21.70 & 20.6 & 20.7 & 22.4 \\
\hline Panamá & 38.3 & 36.5 & 33.8 & 33.4 & 29.8 & 27.60 & 26.5 & 26.2 & 25.8 \\
\hline
\end{tabular}

Fuente: Elaboración propia con base en datos del Banco Mundial: http://datos.bancomundial.org/tema/pobreza; y de CEPAL: http://interwp.cepal.org/sisgen/ConsultaIntegrada.asp?idIndicador $=2599$ \&idioma $=\mathrm{e}$

Tabla 3. Porcentaje de la población en situación de indigencia, 2006-2014.

\begin{tabular}{|l|c|c|c|c|c|c|c|c|c|}
\hline País/año & 2006 & 2007 & 2008 & 2009 & 2010 & 2011 & 2012 & 2013 & 2014 \\
\hline México & 14.00 & - & 18.6 & - & 18.8 & - & 19.7 & - & - \\
\hline Guatemala & 15.20 & - & - & - & - & 13.30 & - & - & - \\
\hline Honduras & 40.40 & 37.5 & 36.2 & 36.4 & 39.1 & 41.64 & 46.0 & 42.6 & - \\
\hline El Salvador & 9.55 & 10.8 & 12.4 & 12.0 & 11.2 & 12.20 & 8.9 & 7.1 & - \\
\hline Nicaragua & - & - & - & 14.6 & - & - & - & - & - \\
\hline Costa Rica & 5.30 & 3.3 & 3.5 & 4.2 & 5.8 & 6.40 & 6.3 & 6.4 & 6.7 \\
\hline Panamá & 17.60 & 15.7 & 15.3 & 15.3 & 12.2 & 11.50 & 11.1 & 11.1 & 11.0 \\
\hline
\end{tabular}

Fuente: Elaboración propia con base en datos de CEPAL: http://interwp.cepal.org/ sisgen/ConsultaIntegrada.asp?idIndicador $=2599$ \&idioma $=e$ 
Tabla 4. Niveles de desigualdad (Índice de Gini), 2006-2014.

\begin{tabular}{|l|c|c|c|c|c|c|c|c|c|}
\hline País/año & 2006 & 2007 & 2008 & 2009 & 2010 & 2011 & 2012 & 2013 & 2014 \\
\hline México & 48.01 & - & 48.23 & - & 48.13 & - & $48.07-$ & & 48.21 \\
\hline Guatemala & 54.89 & - & - & - & - & 52.35 & - & - & 48.66 \\
\hline Honduras & 57.42 & 56.16 & 55.74 & 51.56 & 53.39 & 57.40 & 57.40 & 53.67 & 50.64 \\
\hline El Salvador & 45.44 & 45.24 & 46.65 & 45.93 & 44.53 & 42.43 & 41.80 & 43.51 & 41.84 \\
\hline Nicaragua & - & - & - & 45.73 & - & - & - & - & 47.05 \\
\hline Costa Rica & 49.31 & 49.49 & 49.14 & 50.97 & 48.10 & 48.60 & 48.61 & 49.18 & 48.53 \\
\hline Panamá & 55.06 & 52.97 & 52.63 & 52.03 & 51.91 & 51.83 & 51.90 & 51.66 & 50.70 \\
\hline
\end{tabular}

Fuente: Elaboración propia con base en datos del Banco Mundial: http://datos.bancomundial.org/indicador/SI.POV.GINI

Tabla 5. Índice de desarrollo humano, 2006-2014.

\begin{tabular}{|l|l|l|l|l|l|l|}
\hline País/ańo & 2005 & 2010 & 2011 & 2012 & 2013 & 2014 \\
\hline México & 0.722 & 0.746 & 0.748 & 0.754 & 0.755 & 0.756 \\
\hline Guatemala & 0.576 & 0.611 & 0.617 & 0.624 & 0.626 & 0.627 \\
\hline Honduras & 0.584 & 0.610 & 0.612 & 0.607 & 0.604 & 0.606 \\
\hline El Salvador & 0.638 & 0.653 & 0.658 & 0.662 & 0.664 & 0.666 \\
\hline Nicaragua & 0.595 & 0.619 & 0.623 & 0.625 & 0.628 & 0.631 \\
\hline Costa Rica & 0.723 & 0.750 & 0.756 & 0.761 & 0.764 & 0.766 \\
\hline Panamá & 0.733 & 0.761 & 0.759 & 0.772 & 0.777 & 0.780 \\
\hline
\end{tabular}

Fuente: Elaboración propia con base en datos del PNUD: http://hdr.undp.org/es/data 
Así, podemos concluir que las prioridades del Proyecto Mesoamérica, expresadas en el impulso del comercio y el libre mercado, la competitividad, la apertura de inversión privada, así como la construcción de infraestructura y la explotación de los recursos naturales en beneficio de los grandes capitales, tenían un enfoque más económico que social. De este modo, no sólo no se impulsaron programas que buscaran transformar la realidad social de la región y que remediaran los problemas estructurales, sino que los proyectos ejecutados muchas veces redundaron en su profundización y afectaron negativamente la vida de los pobladores del istmo.

En suma, los programas impulsados por el Proyecto Mesoamérica, beneficiaron a los grandes capitales trasnacionales, incidieron en el fortalecimiento de los tratados de libre comercio y abrieron las puertas a la inversión privada. Lo anterior tuvo importantes repercusiones sociales y, en muchos casos, trajo consigo procesos de privatización, despojo y desplazamiento de comunidades, así como de explotación de los recursos naturales y destrucción del medio ambiente. ${ }^{34}$ Tanto el Plan Puebla Panamá como el Proyecto Mesoamérica no parecen haber estado interesados en solucionar de fondo el problema de la pobreza ni impulsar el desarrollo de Centroamérica de manera sostenida. Existe, pues, una brecha evidente entre los objetivos propuestos y el discurso oficial en términos de desarrollo y progreso social, por un lado, frente a los resultados de los proyectos y los intereses económicos de los grandes capitales que son los que más se han beneficiado de este proyecto de cooperación. ${ }^{35}$ Además, es necesario insistir en que el Proyecto Mesoamérica ignoró dos de los aspectos fundamentales de la realidad centroamericana y de la dinámica de la frontera sur de México que, en el contexto en el que fue impulsado, se configuraron como los temas más relevantes: el fenómeno de la migración y el incremento de la violencia en la región.

\footnotetext{
${ }^{34}$ Ya desde la ejecución de algunos proyectos promovidos por el PPP, se habían dado procesos de explotación y desalojo de comunidades, particularmente en Chiapas (López, 2009: 169-179).

35 Efectos semejantes se habían observado a partir de la implementación del PPP el cual, a pesar de presentar un discurso orientado al impulso del desarrollo social a partir de la ampliación de los proyectos de infraestructura, en los hechos privilegió a la inversión extranjera y creó las condiciones para la explotación de los recursos naturales y humanos en la región centroamericana (idem: 126-127).
} 


\section{Reflexiones finales}

Frente a todo lo anterior, resulta especialmente grave observar que el actual mecanismo de cooperación entre México y Centroamérica, el Proyecto Mesoamérica, excluyó de sus horizontes de preocupación y actuación las iniciativas encaminadas a promover el desarrollo; los fenómenos de la migración y la violencia quedaron fuera de su mirada, y no sólo no se impulsaron proyectos que resolvieran de fondo los problemas estructurales que los originan, sino que tampoco se establecieron programas que los enfrentaran de manera coyuntural. De este modo, se desdibujaron las necesidades y las realidades económicas y sociales más apremiantes de la región.

Los esfuerzos dirigidos a la búsqueda de la integración regional han tenido como base la firma de una serie de tratados y convenios, al tiempo que se ha participado en iniciativas multilaterales de cooperación. Sin embargo, estos intentos no han derivado en una solución de fondo para los problemas económicos y sociales de Centroamérica. Los resultados de los programas de cooperación han sido limitados, muchas veces han estado centrados en aspectos coyunturales, por lo que no han aportado soluciones de largo plazo. Estos mecanismos se han caracterizado por ofrecer buenos diagnósticos de los principales problemas regionales y han logrado atender proyectos específicos, pero no han tenido un impacto en el desarrollo de las economías nacionales $y$, mucho menos, sus resultados se han reflejado a nivel regional.

Una vez firmados los acuerdos de paz, y habiendo dejado atrás la etapa del conflicto armado en la que México otorgó su apoyo a los movimientos sociales en la región, es necesario que México vea a Centroamérica como un aliado de vital importancia en función de los nuevos retos de la agenda regional: la migración y el combate a la violencia. Los proyectos de cooperación como el Plan Puebla Panamá o el Proyecto Mesoamérica han demostrado su inoperancia. Además, por ser demasiado ambiciosos, han requerido de la inversión de una gran cantidad de recursos a los cuales ha sido muy difícil dar seguimiento.

En el nuevo contexto regional y mundial, se precisan acuerdos de cooperación entre los gobiernos de México y Centroamérica, al margen de las políticas promovidas por el gobierno de Estados Unidos y de los 
intereses del capital privado, dirigidos a desarrollar proyectos concretos con la finalidad de solucionar los problemas comunes, tanto coyunturales como estructurales: la pobreza, la marginación, el desempleo y la violencia. Ese es el verdadero reto para la diplomacia mexicana en su relación con los países del istmo: enfrentar los problemas de la posguerra relativos a la migración de centroamericanos en tránsito y a la seguridad de la frontera sur, buscando favorecer el respeto a los derechos humanos, en un marco de defensa de la soberanía y de búsqueda de acciones conjuntas que permitan resolver de fondo los problemas regionales.

\section{Bibliografía citada}

Alba Vega, Carlos y Dirk Kruijt, 2007, "Viejos y nuevos actores violentos en América Latina: temas y problemas", Foro Internacional 189, julio-septiembre, vol. XLVII, núm. 3, pp. 485-516.

Ángeles Cruz, Hugo, 2004, "Las bandas maras salvatruchas en la región fronteriza del Soconusco, Chiapas”, en José E. Sánchez y Ramón Jarquín Gálvez (editores), La frontera sur. Reflexiones sobre el Soconusco, Chiapas y sus problemas ambientales, poblacionales y productivos, El Colegio de la Frontera Sur, México, pp. 143-156. Arana, Ana, 2005, "Cómo las pandillas invadieron América Central", Foreign Affairs en español, julio-septiembre, vol. 5, núm. 3, pp. 116-130.

Armijo Canto, Natalia, 2015, "Dinámica de seguridad en la frontera sur de México en el siglo XXI”, en Mónica Toussaint y Natalia Armijo (coordinadoras), Centroamérica después de la firma de los Acuerdos de Paz. Violencia, fronteras y migración, Instituto Mora, Universidad de Quintana Roo, México, pp. 195-224.

Armijo Canto, Natalia y Mónica Toussaint (coordinadoras), 2015, Centroamérica después de la firma de los Acuerdos de Paz. Violencia, fronteras y migración, Instituto Mora, Universidad de Quintana Roo, México.

Bailey, John, “¿Qué es la Iniciativa Mérida?”, El Universal, 26 de febrero de 2008.

Benítez Manaut, Raúl, 2007, "Pros y contras de la Iniciativa Mérida", Enfoque-Reforma, núm. 715, 9 de diciembre, pp. 13-15. 
Benítez Manaut, Raúl, 2009, “La iniciativa Mérida: nuevo paradigma en la relación de seguridad México-Estados Unidos-Centroamérica", Revista Mexicana de Política Exterior, núm. 87, pp. 215-242.

Casillas, Rodolfo, 2006, Una vida discreta, fugaz y anónima: Los centroamericanos transmigrantes en México, Flacso, México.

Castillo, Manuel Ángel, 2000, "Las políticas hacia la migración centroamericana en países de origen, de destino y de tránsito", Papeles de Población, abril-junio, núm. 24, pp. 133-157.

Castillo, Manuel Ángel, 2005a, "Actores y políticas en torno a la migración en la frontera sur de México", en Diana Guillén (coordinadora), Chiapas: frontera en movimiento, Instituto Mora, México, pp. 59-98.

Castillo, Manuel Ángel, 2005b, "Fronteras, migración y seguridad en México", Alteridades, julio-diciembre, vol. 15, núm. 30, pp. 51-60.

Castillo, Manuel Ángel, 2006, "Mexico: caught between the United States and Central America", Migration Information Source, abril.

Castillo, Manuel Ángel y Coralia A. Herrera, 2006, Centroamericanos en México y en Estados Unidos: tendencias y politicas migratorias, CEDUA Colmex, México.

Castillo, Manuel Ángel y Mónica Toussaint, 2009, Diagnóstico sobre las migraciones centroamericanas en el estado de Chiapas y sus impactos socio-culturales, Ministerio de Asuntos Exteriores y de Cooperación (AECID) Espańa, Mirando al Sur, México.

Castillo, Manuel Ángel y Mónica Toussaint, 2010, "Seguridad y migración en la frontera sur”, en Arturo Alvarado y Mónica Serrano (coordinadores), Seguridad nacional y seguridad interior, El Colegio de México, México, pp. 269-300.

Comisión de Jefes y Jefas de Policía de Centroamérica y Caribe, 2003, Informe del Equipo Técnico para el Estudio y Evaluación de la Actividad Delictiva de las Pandillas y/o Maras, Panamá.

Comisión Económica para América Latina y el Caribe, 2015, "Una mirada a los países del Proyecto Mesoamérica", Documento elaborado para la XV Cumbre del Mecanismo de Diálogo y Concertación de Tuxtla, 26 de junio, Guatemala. 
Cruz, José Miguel, 2005, "Los factores asociados a las pandillas juveniles en Centroamérica", Estudios Centroamericanos, noviembrediciembre, núm. 685-686, pp. 1155-1182.

Cruz, José Miguel y Nelson Portillo Peńa, 1998, Solidaridad y violencia en las pandillas del gran San Salvador. Más allá de la vida loca, UCA Editores, San Salvador.

Dardón S., J. Jacobo (coordinador), 2002, La frontera de Guatemala con México; aportes para su caracterización, Facultad Latinoamericana de Ciencias Sociales (Flacso) Guatemala, Guatemala.

"Declaración de Villahermosa", 2008, X Cumbre del Mecanismo de Diálogo y Concertación de Tuxtla, 28 de junio.

Díaz, Gabriela y Gretchen Kuhner, 2007, "Women migrants in transit and detention in Mexico", Migration Information Source, marzo.

Encuesta sobre migración en la frontera Guatemala-México 2004, 2006, Instituto Nacional de Migración, Consejo Nacional de Población, El Colegio de la Frontera Norte, Secretaría de Gobernación, Secretaría del Trabajo y Previsión Social, Secretaría de Relaciones Exteriores, México.

Girardi, Mara, 2007, "Mujeres migrantes en la frontera sur de México. Víctimas y transgresoras, entre la autonomía y la trata-tráfico", en Marisa Belausteguigoitia y Lucía Melgar (coordinadoras), Fronteras, violencia, justicia: nuevos discursos, Programa Universitario de Estudios de Género UNAM, Fondo de Desarrollo de las Naciones Unidas para la Mujer (Unifem), México, pp. 151-175. Gómez, Natalia, "Otorgará Iniciativa Mérida 500 mdd a México en primer año", El Universal, 22 de octubre de 2007.

Instituto Tecnológico Autónomo de México, 2014, "Migración centroamericana en tránsito por México hacia Estados Unidos: Diagnóstico y recomendaciones. Hacia una visión integral, regional y de responsabilidad compartida”, Documento ejecutivo, ITAM, México.

Iruegas, Gustavo, "Fait Accompli”, La Jornada, 5 de diciembre de 2007. López Castellanos, Nayar, 2009, Del Plan Puebla Panamá al Proyecto Mesoamérica. Un espejo de la globalización neoliberal, Plaza y Valdés, México. 
Martín Álvarez, Alberto, Ana Fernández Zubieta y Karla Villareal Sotelo, 2007, "Difusión transnacional de identidades juveniles en la expansión de las maras centroamericanas", Perfiles Latinoamericanos, julio-diciembre, núm. 30, pp. 101-121.

Orduña, Joaquín, 2008, “Tratados de Libre Comercio entre México y otros países”, en Rodrigo Páez y Mario Vázquez Olivera (coordinadores), Integración Latinoamericana. Organismos y Acuerdos (1948-2008), CIALC UNAM, México, pp. 263-266.

Páez, Rodrigo y Mario Vázquez (coordinadores), 2008, Integración Latinoamericana. Organismos y Acuerdos (1948-2008), CIALC UNAM, México.

Rico, Carlos, 2008, "La iniciativa Mérida y el combate nacional al crimen organizado", Foreign Affairs en español, enero-marzo, vol. 8, núm. 1, pp. 3-13.

Rodríguez Chávez, Ernesto, 2006, "Frontera sur y política migratoria en México", Foreign Affairs en español, octubre-diciembre, vol. 6, núm. 4, pp. 64-70.

Rodríguez de Ita, Guadalupe, 2005, "Militares en la frontera”, en Diana Guillén (coordinadora), Chiapas: frontera en movimiento, Instituto Mora, México, pp. 99-152.

Ruiz Marrujo, Olivia, 2001, "Los riesgos de cruzar. La migración centroamericana en la frontera México-Guatemala", Frontera Norte, enero-junio, vol. 13, núm. 25, pp. 7-33.

Savenije, Wim, 2007, "Las pandillas transnacionales o 'maras': violencia urbana en Centroamérica”, Foro Internacional 189, julioseptiembre, vol. XLVII, núm. 3, pp. 637-659.

Secretaría de Relaciones Exteriores, 2012, Proyecto de Integración y Desarrollo de Mesoamérica, Libro Blanco, 1 de diciembre de 2006 a 30 de junio de 2012, SRE, México.

Serna, Eva María, 2008, "El Plan Puebla-Panamá (PPP), ahora Proyecto Mesoamérica”, en Rodrigo Páez y Mario Vázquez (coordinadores), Integración Latinoamericana. Organismos y Acuerdos (1948-2008), CIALC UNAM, México, pp. 219-228.

Toussaint, Mónica, 2017, “¿Activismo o intervencionismo? México frente a Nicaragua, 1979-1982”, en Mario Vázquez Olivera 
(coordinador), México ante Centroamérica. Testimonio de una época, CIALC UNAM, México, pp. 49-77.

Vericat, Isabel, 2007, Bajo el Tacaná. La otra frontera: México-Guatemala, Ediciones sin nombre/17, Instituto de Estudios Críticos, México.

\section{Referencias electrónicas}

Aguilar, Marco Antonio, 2003, "Consecuencias del Tratado de Libre Comercio Triángulo Norte de Centroamérica y México", Facultad de Ciencias Económicas y Empresariales Universidad Rafael Landívar, [en línea] disponible en http://www.url.edu.gt/ PortalURL/Archivos/83/Archivos/Departamento\%20de\%20 Investigaciones $\% 20 \mathrm{y} \% 20$ publicaciones/Articulos\%20Doctrinarios/Econ\%C3\%B3micas/TLC\%20Mexico\%20Triangulo\%20 Norte\%20CA.pdf [fecha de consulta: 20 de enero de 2017].

Banco Mundial, "Datos de incidencia de la pobreza", disponibles en http://datos.bancomundial.org/tema/pobreza [fecha de consulta: 10 de enero de 2017].

Banco Mundial, "Datos de Índice Gini”, disponibles en http://datos. bancomundial.org/indicador/SI.POV.GINI [fecha de consulta: 10 de enero de 2017].

Castillo, Manuel Ángel, 2003, "Los desafíos de la emigración centroamericana en el siglo XXI", Amérique Latine Histoire et Mémoire, núm. 7, disponible en http://alhim.revues.org/document369. html [fecha de consulta: 12 de julio de 2008].

Comisión Económica para América Latina y el Caribe, CEPALCEPALSTAT, Bases de datos, "Población en situación de indigencia y pobreza según área geográfica”, disponibles en http://interwp.cepal.org/sisgen/ConsultaIntegrada. asp?idIndicador $=2599$ \&idioma $=\mathrm{e}$ [fecha de consulta: 10 de enero de 2017].

Instituto Nacional de Estadística y Geografía, Inegi, "Datos de defunciones por homicidio", disponibles en http://www.inegi. org.mx/lib/olap/consulta/general_ver4/MDXQueryDatos. asp?proy $=$ [fecha de consulta: 5 de enero de 2017]. 
Ministerio de Justicia y Seguridad Pública, 2012, "Secretario General de la OEA llega hoy a nuestro país para conocer proceso de tregua entre pandillas y participar en acto por la paz y el cese de la violencia", [en línea] disponible en http://www.seguridad.gob.sv/index.php?option=com_content\&view=article \&catid=52: noticias\&id=2142: secretario-general-de-al-oea-llega-hoy-a-nuestro-pais-para-conocer-proceso-de-tregua-entrepandillas-y-participar-en-acto-por-la-paz-y-el-cese-de-la-violencia\&Itemid $=77$ [fecha de consulta: 20 de enero de 2017].

Oficina de las Naciones Unidas contra la Droga y el Delito, 2012, "Delincuencia Organizada Transnacional en Centroamérica y el Caribe. Una Evaluación de las Amenazas", Informe de UNODC, [en línea] disponible en https://www.unodc.org/ documents/data-and-analysis/Studies/TOC_Central_America_and_the_Caribbean_spanish.pdf [fecha de consulta: 20 de enero de 2017].

Oficina de las Naciones Unidas contra la Droga y el Delito, 2014, "Global Study on homicide", 2013, informe de UNODC, [en línea] disponible en http://www.unodc.org/documents/gsh/ pdfs/2014_GLOBAL_HOMICIDE_BOOK_web.pdf [fecha de consulta: 20 de enero de 2017].

Pie de Página, "Éxodos, crónicas y reportajes de migraciones", disponible en http://www.piedepagina.mx/exodos.php [fecha de consulta: 3 de enero de 2017].

Portal Oficial del Proyecto Mesoamérica, disponible en http://proyectomesoamerica.org/joomla/ [fecha de consulta: 4 de enero de 2017].

Programa de las Naciones Unidas para el Desarrollo, PNUD, "Datos sobre el Desarrollo Humano (1985-2015)”, disponibles en http://hdr.undp.org/es/data [fecha de consulta: 10 de enero de 2017].

Registro Nacional de Datos de Personas Extraviadas o Desaparecidas, RNPED, "Estadísticas de personas desaparecidas", disponibles en https://www.gob.mx/sesnsp/acciones-y-programas/registro- 
nacional-de-datos-de-personas-extraviadas-o-desaparecidasrnped?idiom=es [fecha de consulta: 12 de enero de 2017].

Rodríguez Chávez, Ernesto, Salvador Berumen Sandoval y Luis Felipe Ramos Martínez, 2011, "Migración centroamericana de tránsito irregular por México. Estimaciones y características generales", Apuntes sobre Migración, núm. 1, INM-CEM, [en línea] disponible en http://www.gobernacion.gob.mx/work/models/ SEGOB/Resource/2101/1/images/APUNTES_N1_Jul2011. pdf [fecha de consulta: 20 de enero de 2017].

Secretaría de Gobernación, Segob, "Boletines estadísticos anuales", disponibles en http://www.politicamigratoria.gob.mx/es_mx/ SEGOB/Boletines_Estadisticos [fecha de consulta: 3 de enero de 2017].

Secretaría de Relaciones Exteriores, SRE, “Tratados y convenios internacionales celebrados por México", disponibles en http://www. sre.gob.mx/tratados [fecha de consulta: 10 de enero de 2017]. 